\title{
Hydroxylated and methoxylated polybrominated diphenyl ethers in mollusks from Chinese coastal areas
}

\author{
Jianteng Sun, Jiyan Liu*, Yanwei Liu, Guibin Jiang \\ State Key Laboratory of Environmental Chemistry and Ecotoxicology, Research Center for Eco-Environmental Sciences, Chinese Academy of Sciences, P.O. Box 2871, \\ Beijing 100085, China
}

\section{H I G H L I G H T S}

- OH-PBDEs and MeO-PBDEs were determined in mollusks from Chinese coastal areas.

- Significant correlations were found between $\mathrm{OH}-$ and MeO-PBDEs.

- Crassostrea talienwhanensis accumulated more OH- and MeO-PBDEs.

- Temporal trends of $\mathrm{OH}-$ and MeO-PBDEs in mollusks were studied.

\section{A R T I C L E I N F O}

\section{Article history:}

Received 21 December 2012

Received in revised form 26 February 2013

Accepted 16 March 2013

Available online 10 April 2013

\section{Keywords:}

OH-PBDEs

MeO-PBDEs

Mollusks

Temporal trend

\begin{abstract}
A B S T R A C T
Hydroxylated polybrominated diphenyl ethers (OH-PBDEs), methoxylated PBDEs (MeO-PBDEs) and PBDEs were determined in three mollusk species collected from three Chinese coastal regions in 2007, 2009, 2010 and 2011. The dominant MeO- and OH-PBDEs isomers detected in mollusks were 6-MeOBDE-47, 2'-MeO-BDE-68, 6-OH-BDE-47 and 2'-OH-BDE-68. Concentrations of $\Sigma$ MeO-PBDEs ranged from 9.20 to $2090 \mathrm{pg} \mathrm{g}^{-1}$ dry weight (mean: $450 \mathrm{pg} \mathrm{g}^{-1}$ dry weight). Concentrations of $\Sigma O H-P B D E s$ ranged from 118 to $2540 \mathrm{pg} \mathrm{g}^{-1}$ dry weight (mean: $534 \mathrm{pg} \mathrm{g}^{-1}$ dry weight). Species differences in accumulation were found for the three mollusk species. Spatial distribution showed that $\mathrm{OH}$ - and MeO-PBDEs levels were higher in Weihai than in Tianjin. The temporal trends of $\mathrm{OH}-$ and MeO-PBDEs in mollusks were studied during period of 2007 to 2011, rising of $\Sigma O H-P B D E s$ in Rap from Penglai and Ost from Weihai and declining of $\Sigma \mathrm{MeO}-\mathrm{PBDEs}$ in Ost in Penglai were observed. Significant correlations were found between $\mathrm{OH}-$ and MeO-PBDEs, but neither between PBDEs and OH-PBDEs, nor between PBDEs and MeO-PBDEs, suggesting that $\mathrm{OH}-$ and MeO-PBDEs may have a common source or similar accumulation behavior in mollusks. OH- and MeO-PBDEs were likely not to originate from PBDE precursors.
\end{abstract}

(c) 2013 Elsevier Ltd. All rights reserved.

\section{Introduction}

Polybrominated diphenyl ethers (PBDEs) are a group of brominated flame retardants (BFRs) utilized in a variety of consumer products for the past several decades. PBDEs are toxic, persistent, and bioaccumulative, and have been ubiquitously distributed in the environment (Hites, 2004; de Wit et al., 2006). Structural analogues to PBDEs, mainly tetrabromo- and pentabromo-hydroxylated $(\mathrm{OH})$-PBDEs and methoxylated (MeO) PBDEs, have also been detected in algae, sponge, fish, bird, and mammal species from diverse aquatic environments (Unson et al., 1994; Sinkkonen et al., 2004; Wolkers et al., 2004; Malmvarn et al., 2005; Teuten et al., 2005).

For most toxicological endpoints, OH-PBDEs are more potent than the corresponding PBDEs. OH-PBDEs structurally resemble

\footnotetext{
* Corresponding author. Tel.: +86 10 62849334; fax: +86 1062849339 .

E-mail address: liujy@rcees.ac.cn (J. Liu).
}

the thyroid hormone (TH), thyroxin (T4), and have been found to bind to transthyretin (TTR) (Hamers et al., 2008; Ucan-Marin et al., 2009; Li et al., 2010). OH-PBDEs also elicit many other toxic effects such as interruption of oxidative phosphorylation (Van Boxtel et al., 2008), estrogenic and antiestrogenic activity (Meerts et al., 2001) and neurotoxicity (Dingemans et al., 2008; Hendriks et al., 2010) in exposed wildlife and humans.

The origin of these $\mathrm{OH}-$ and MeO-PBDEs is under discussion, and two major sources have been suggested. Firstly, occurrence of higher concentrations of OH-PBDEs and MeO-PBDEs than PBDEs in marine organisms has led to the finding that these compounds may be formed naturally by marine algae or cyanobacteria (Malmvarn et al., 2005, 2008). Radiocarbon measurements of 6-MeOBDE-47 and 2'-MeO-BDE-68 in whale collected from the North Atlantic demonstrated that these compounds were of natural origin (Teuten et al., 2005). Secondly, OH- and MeO-PBDEs were potential transformation products in organisms. OH-PBDEs were identified as metabolites of PBDEs in rats and mice (Orn and 
Klasson-Wehler, 1998; Hakk et al., 2002; Morck et al., 2003). MeOPBDEs were also found in maize exposed to PBDEs (Wang et al., 2012). In addition, Wan et al. (2009) proposed that demethylation of MeO-PBDEs by cytochrome P450 rather than parent PBDEs contributed to the formation of OH-PBDEs. It was also shown that interconversion between 6-OH-BDE-47 and 6-MeO-BDE-47 could be observed in Japanese medaka (Wan et al., 2010). The origins of OH-PBDEs and MeO-PBDEs in marine biota have been of increasing scientific interest.

Mollusks have been commonly used to assess contamination in aquatic systems due to their relatively high lipid content and low metabolic enzyme activities (Isobe et al., 2007). The levels of PBDEs were investigated in a portion of samples in an earlier study of our group; however, no previous examination on $\mathrm{OH}-$ and $\mathrm{MeO}-\mathrm{PBDEs}$ contaminations in selected mollusks from the study region has been reported. This study attempts to investigate and elucidate (1) contamination status, (2) species difference in accumulation, (3) spatial distribution, (4) temporal trends, and (5) possible source and potential exposure risks of $\mathrm{OH}$ - and $\mathrm{MeO}-\mathrm{PBDEs}$ for the environment and human health, by analyzing PBDEs, OH-PBDEs and MeO-PBDEs in mollusks collected in Chinese coastal areas.

\section{Experimental section}

\subsection{Chemicals and reagents}

Target chemical standards included nine OH-PBDE congeners (4-OH-BDE-42, 4'-OH-BDE-49, 3-OH-BDE-47, 5-OH-BDE-47, 6OH-BDE-47, 2'-OH-BDE-68, 6-OH-BDE-85, 5'-OH-BDE-99, and 6'-OH-BDE-99), nine MeO-PBDE congeners (4-MeO-BDE-42, 4'MeO-BDE-49, 3-MeO-BDE-47, 5-MeO-BDE-47, 6-MeO-BDE-47, 2'-MeO-BDE-68, 6-MeO-BDE-85, 5'-MeO-BDE-99, and 6'-MeOBDE-99) and five PBDE congeners (BDE-47, 66, 71, 85, 99). Based on the selected congeners of $\mathrm{OH}$ - and $\mathrm{MeO}-\mathrm{PBDEs}$, only corresponding tetra- and penta-BDEs which were abundant in the environment were selected here as target compounds to assess the statistical relationships among PBDEs, OH-PBDEs and MeO-PBDEs. Surrogate standards were ${ }^{13} \mathrm{C}-6-\mathrm{OH}-\mathrm{BDE}-47$ and BDE-75. Chemical standards used in the present study were purchased from AccuStandard (New Haven, CT, USA) and Wellington (Guelph, ON, Canada). All solvents were HPLC grade or pesticide grade and were obtained from Honeywell Burdick \& Jackson (Seelze, Germany) and J.T. Baker (Phillipsburg, NJ, USA). Silica gel (100-200 mesh size) was purchased from Merck (Darmstadt, Germany).

\subsection{Sampling}

In August 2007, 2009, 2010 and 2011, three species of mollusks were collected separately from three coastal sites (Fig. 1) near the cities of Tianjin, Weihai and Penglai. Tianjin is located in Bohai Bay. Weihai is located along the Chinese Yellow Sea. Penglai is located near the boundary of Bohai Sea and Yellow Sea. The three selected species of mollusks were Neverita didyma (Nev), Rapana venosa (Rap) and Crassostrea talienwhanensis (Ost). The mollusks were transported to the laboratory on ice, and then cleaned by water in the laboratory. The soft tissue of the mollusks was thoroughly rinsed with Milli-Q water to remove impurities. For each species from a sampling site, about $1000 \mathrm{~g}$ of wet soft tissue (consisting of 5-10 individuals) was homogenized in a blender to form one composite sample. The samples were kept at $-20^{\circ} \mathrm{C}$ until analysis. A total of 36 composite soft tissue samples were obtained and analyzed.

\subsection{Sample preparation}

All samples were freeze-dried, homogenized and sieved. Sample pretreatment was based on our previous developed methods (Sun et al., 2012a) with modifications. Briefly, an aliquot of $2 \mathrm{~g}$ of mollusk sample was spiked with surrogate standard and extracted thrice with $10 \mathrm{~mL}$ of hexane/MTBE $(1: 1 ; \mathrm{v} / \mathrm{v})$ after the addition of $2 \mathrm{~mL}$ 2-propanol. The extracts were combined and dried under gentle flow of nitrogen gas. The dried residues were then dissolved in $20 \mathrm{~mL}$ of DCM and cleaned by acidified silica gel (10 g, 44\% $\mathrm{H}_{2} \mathrm{SO}_{4}$ acidified). Then, a glass column filled with anhydrous $\mathrm{Na}_{2-}$ $\mathrm{SO}_{4}$ was used to filter the extract. The concentrated extract was further cleaned up and fractionated by elution with $60 \mathrm{~mL}$ of $80 \%$ hexane in DCM and $70 \mathrm{~mL}$ of DCM on a column packed with, from bottom to top, $5 \mathrm{~g}$ of silica deactivated with $5 \%$ water $(\mathrm{w} / \mathrm{w})$ and $1 \mathrm{~g}$ of anhydrous sodium sulfate. PBDEs and MeO-PBDEs were eluted in the first fraction and concentrated to a volume of $100 \mu \mathrm{L}$ for subsequent gas chromatography/mass spectrometry (GC/MS) analysis. OH-PBDEs were eluted in the second fraction. The eluate was concentrated to dryness by evaporation and gentle stream of nitrogen gas and solvent exchanged to $100 \mu \mathrm{L}$ of acetonitrile prior to liquid chromatography/tandem quadrupole mass spectrometry (LC-MS/ MS) determination.

\subsection{Instrumental analysis}

OH-PBDEs were analyzed using a high-performance liquid chromatograph (Agilent 1290) coupled with a triple-quadrupole mass spectrometer (Agilent 6460). The quantification of PBDEs and MeO-PBDEs was carried out using a gas chromatograph (Agilent 6890) equipped with a mass spectrometer detector (Agilent 5973C) operated in electron capture negative ionization (ECNI) mode. More detailed descriptions of the instrument operational procedures can be found in our previously developed method (Sun et al., 2012a,b).

\subsection{Quality assurance and quality control (QA/QC)}

QA/QC was implemented to ensure the correct identification and accurate quantification of the target compounds. All pretreatment equipments rinses were carried out with acetone and hexane to avoid cross contamination. A laboratory blank and a matrix spike were injected for every batch of 6 samples during the instruments analysis. No target compounds were found in blanks and no memory effects were observed between consecutive runs. Identification was based on a comparison of the retention times and mass spectra of analytes in samples to those of authentic standards. All analyte concentrations were recovery corrected. The method detection limits (MDLs) for all the investigated analytes by GCMS and LC-MS/MS was estimated based on a signal-to-noise ratio $(S / N)$ of 3 using the lowest concentration standard. For OH-PBDEs, MDLs were 3.83-6.72 pg g $^{-1}$ dry weight (dw). For PBDEs and MeOPBDEs, MDLs were $1.22-8.61 \mathrm{pg} \mathrm{g}^{-1} \mathrm{dw}$. Recoveries for spiked samples were 71.4-94.7\% for PBDEs and MeO-PBDEs, and 67.5$85.6 \%$ for OH-PBDEs. The results of PBDEs analysis were in good agreement with those for reported values as described in previous report done by our group (Zhu et al., 2012).

\section{Results and discussion}

\subsection{Congener profiles and concentrations}

Fig. 2 shows concentrations of detected $\Sigma$ MeO-PBDEs, $\Sigma O H-$ PBDEs and $\Sigma$ PBDEs in all analyzed mollusk samples. Composition profiles of MeO-PBDE and OH-PBDE congeners in each mollusk sample are shown in Fig. 3.

The detected MeO-PBDE congeners were 6-MeO-BDE-47, 2'-MeO-BDE-68, 4-MeO-BDE-42, 5-MeO-BDE-47, 4'-MeO-BDE49, 6-MeO-BDE-85, 5'-MeO-BDE-99 and 6'-MeO-BDE-99, with 


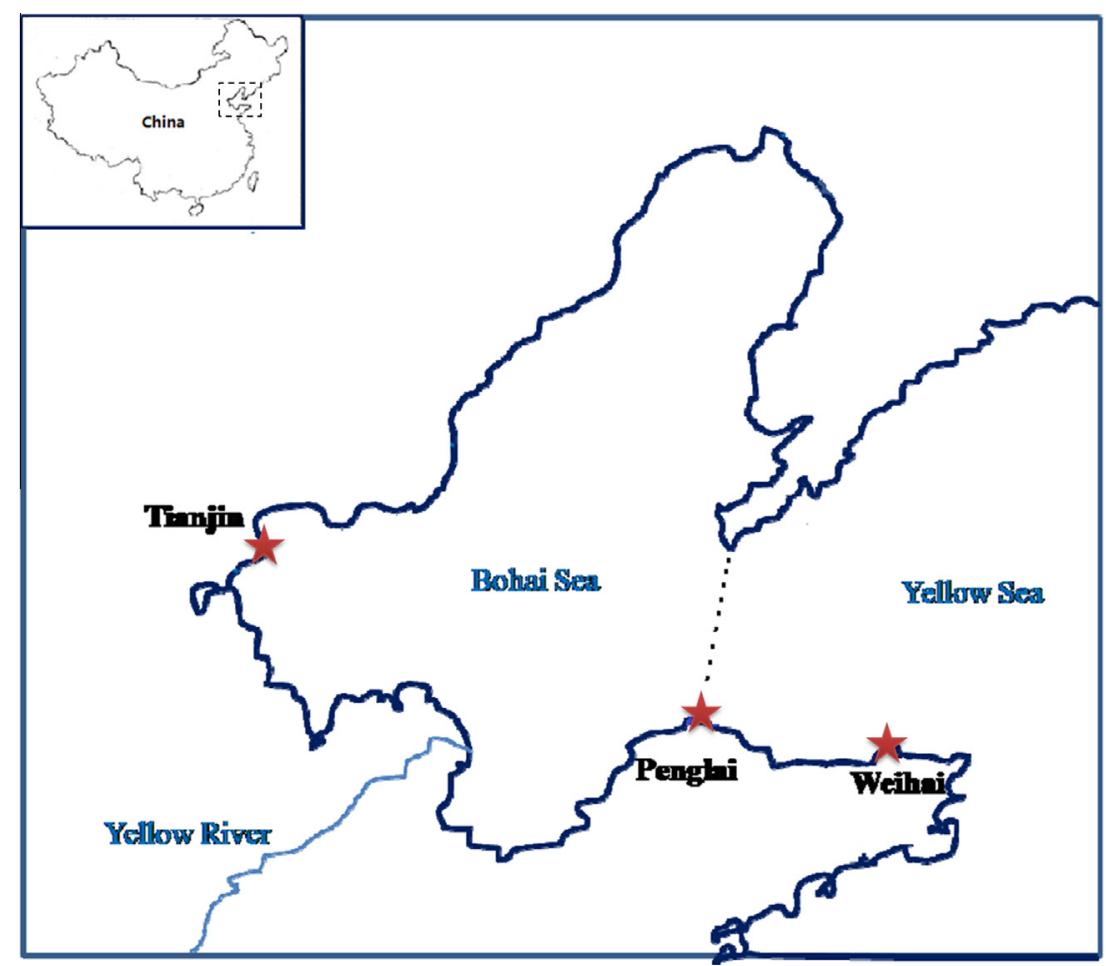

Fig. 1. Map of sampling locations in Chinese coastal areas. ( $\star$, sampling site).

detection frequency of $97 \%, 94 \%, 36 \%, 28 \%, 6 \%, 8 \%, 8 \%$ and $33 \%$, respectively. 6-MeO-BDE-47 (concentration range from $<$ LOD to $947 \mathrm{pg} \mathrm{g}^{-1}$ dry weight (dw); mean: $167 \mathrm{pg} \mathrm{g}^{-1} \mathrm{dw}$ ) and $2^{\prime}-\mathrm{MeO}-$ BDE-68 (concentration range from <LOD to $750 \mathrm{pg} \mathrm{g}^{-1} \mathrm{dw}$; mean: $188 \mathrm{pg} \mathrm{g}^{-1} \mathrm{dw}$ ) were the most predominant congeners. The combined levels of 6-MeO-BDE-47 and 2'-MeO-BDE-68 accounted for $47-100 \%$ of the sum of all identified MeO-PBDEs. Higher contributions of the two MeO-PBDE congeners have been reported in bivalve (Mytilis edulis) from the Canadian Arctic marine food web (Kelly et al., 2008) and mollusk species (Ruditapes philippinarum,
Mactra veneriformis Reeve and Rapana venosa) from Chinese Liaodong Bay (Zhang et al., 2010a). The profiles of MeO-PBDEs were also similar to those in other marine organism such as red algae and cyanobacteria in the Baltic Sea (Malmvarn et al., 2008), fish from Japanese coastal waters (Nomiyama et al., 2011b), albatross from the Indian and South Atlantic Oceans (Wan et al., 2009), and polar bear from Northern and Western Alaska (Wan et al., 2009). Concentrations of $\Sigma \mathrm{MeO}$-PBDEs ranged from 9.20 to $2090 \mathrm{pg} \mathrm{g}^{-1} \mathrm{dw}$ (mean: $450 \mathrm{pg} \mathrm{g}^{-1} \mathrm{dw}$ ) in mollusks in this study, which were greater than those in sediment from nearby Liaodong

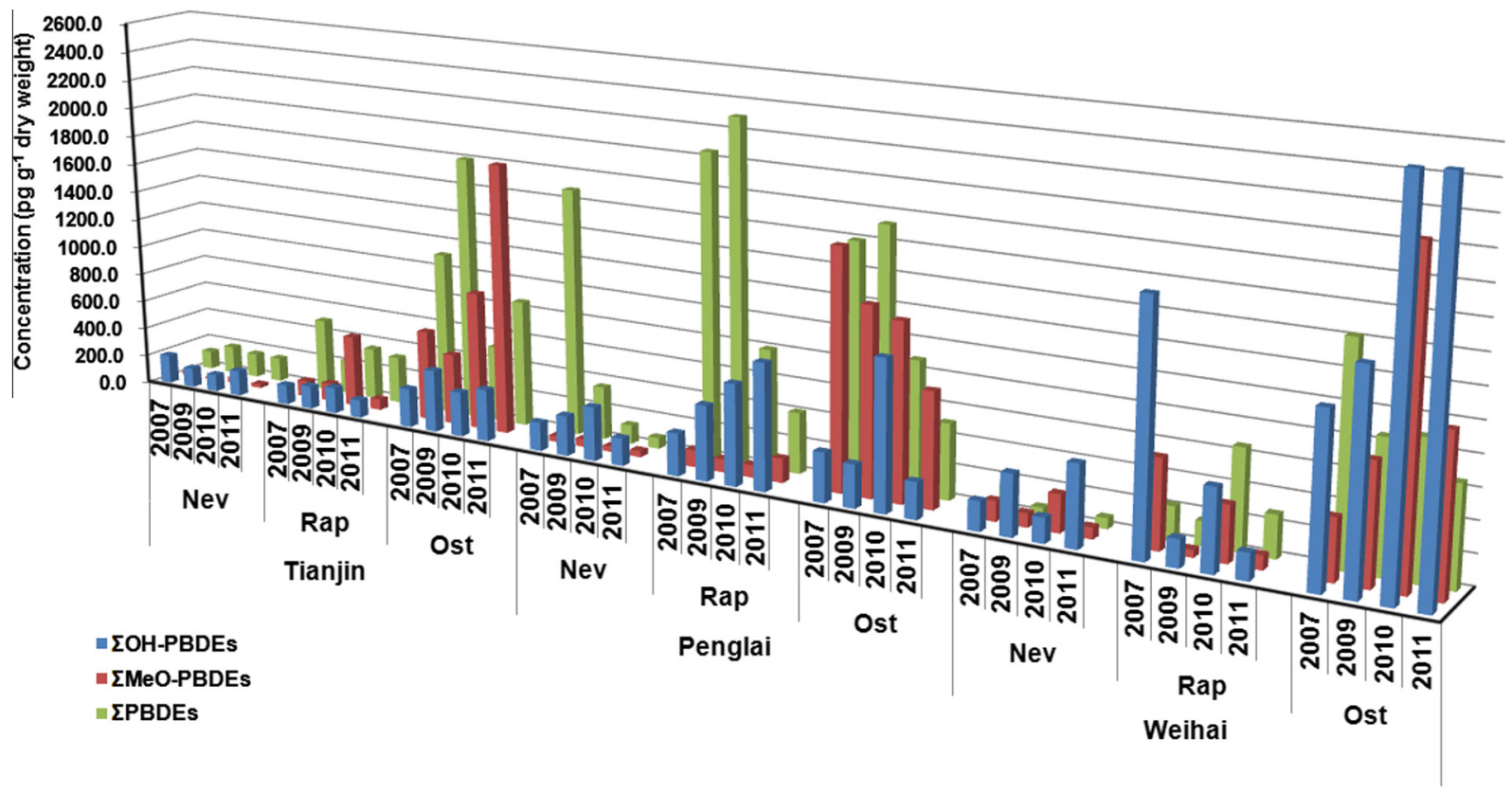

Fig. 2. Concentrations of detected $\Sigma \mathrm{MeO}-\mathrm{PBDEs}, \Sigma \mathrm{OH}-\mathrm{PBDEs}$ and $\Sigma$ PBDEs in mollusk samples. 


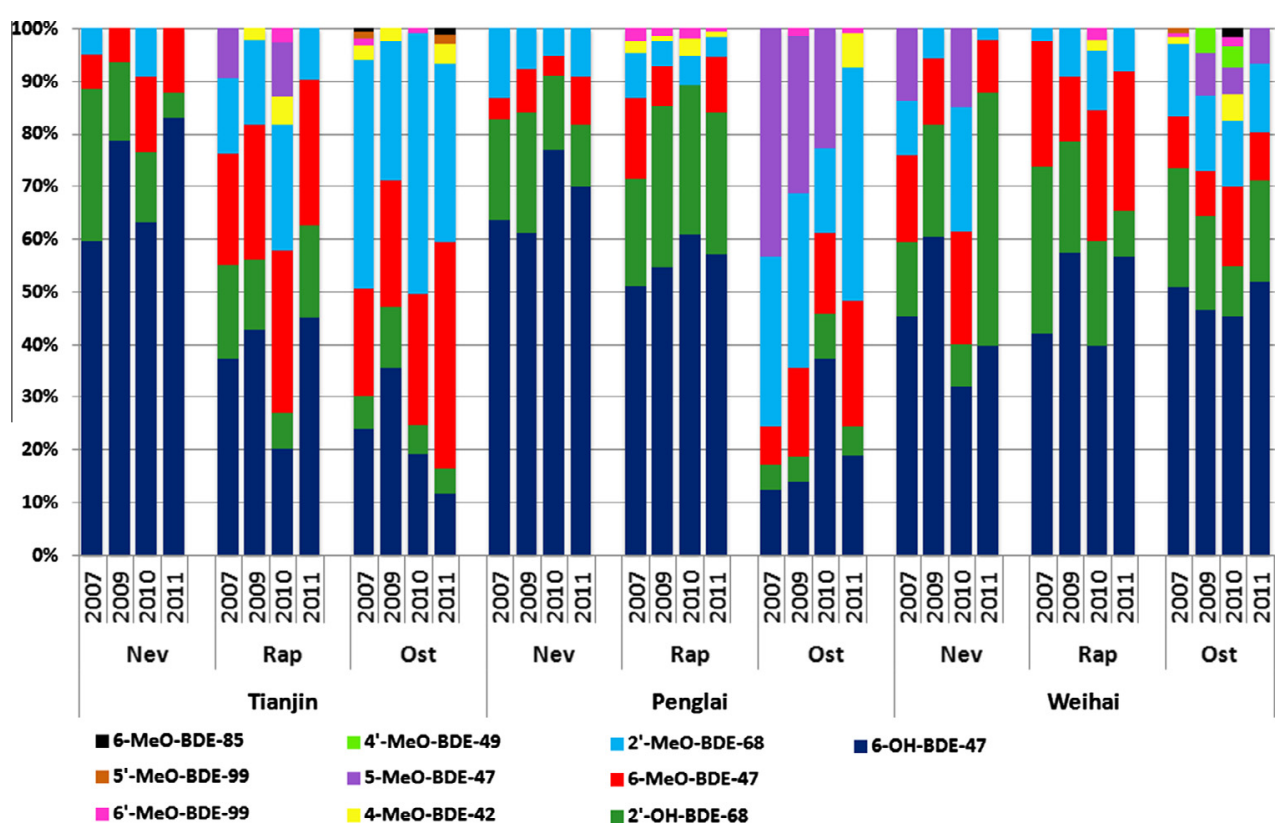

Fig. 3. Composition profiles of MeO-PBDE and OH-PBDE congeners in mollusk samples.

Bay (3.8-56 $\mathrm{pg} \mathrm{g}^{-1} \mathrm{dw}$ ) (Zhang et al., 2012). When concentrations were expressed on a lipid weight (lw) basis, the average concentrations of $\Sigma \mathrm{MeO}-\mathrm{PBDEs}$ in mollusk in this work $\left(3.63 \pm 3.53 \mathrm{ng} \mathrm{g}^{-1} \mathrm{lw}\right)$ were lower than those in mollusks from Liaodong Bay (15.9 $\left.\pm 11.8 \mathrm{ng} \mathrm{g}^{-1} \mathrm{lw}\right)$ (Zhang et al., 2010a) and in mollusk from the Canadian Arctic (mean: $14 \mathrm{ng} \mathrm{g}^{-1} \mathrm{lw}$ ) (Kelly et al., 2008).

Two of nine target OH-PBDE congeners, 6-OH-BDE-47 and 2'OH-BDE-68, were found in all mollusk samples. Concentrations of 6-OH-BDE-47 were in the range of $89.7-2090 \mathrm{pg} \mathrm{g}^{-1} \mathrm{dw}$ (mean: $388 \mathrm{pg} \mathrm{g}^{-1} \mathrm{dw}$ ). Concentrations of $2^{\prime}-\mathrm{OH}-\mathrm{BDE}-68$ were in the range of $10.0-701 \mathrm{pg} \mathrm{g}^{-1} \mathrm{dw}$ (mean: $147 \mathrm{pg} \mathrm{g}^{-1} \mathrm{dw}$ ). 6-OH-BDE-47 and 2 '-OH-BDE-68 have also been reported as predominant OH-PBDE congeners frequently detected in aquatic organisms. Higher proportions of the two compounds were observed in fish collected from the Detroit River (Valters et al., 2005), ringed seals from the Baltic Sea (Routti et al., 2009), Chinese sturgeon from the Yangtze River (Zhang et al., 2010b), and cetaceans from Japanese coastal waters (Nomiyama et al., 2011a). On the basis of lipid weight, the corresponding average values of $\Sigma \mathrm{OH}-\mathrm{PBDEs}$ in mollusks $\left(5.81 \pm 5.43 \mathrm{ng} \mathrm{g}^{-1} \mathrm{lw}\right)$ were greater than those in Chinese sturgeon from the Yangtze River $\left(0.81 \pm 0.18 \mathrm{ng} \mathrm{g}^{-1} \mathrm{lw}\right)$ (Zhang et al., 2010b) and in beluga whales from the Canadian Arctic $\left(<0.001-0.23 \mathrm{ng} \mathrm{g}^{-1}\right.$ lw) (Kelly et al., 2008). For the selected PBDE congeners which were potential precursors of the commonly identified $\mathrm{MeO}$ - and OH-PBDEs in mollusks, the concentrations and profile of individual PBDE were similar to those previously reported (Zhu et al., 2012). BDE-47 was the primary contaminant with detection frequency of $100 \%$. Concentrations ranges of $\Sigma$ PBDEs were $63.9-2300 \mathrm{pg} \mathrm{g}^{-1}$ for all mollusk samples, comparable to the concentrations of $\mathrm{OH}-$ PBDEs and MeO-PBDEs. While the reported proportions of metabolites during biotransformation of PBDEs were generally very small in the lab exposure experiments. For example, the concentration ratios between metabolites (2'-OH-BDE-66, 3-OH-BDE-47, 4-OHBDE-42, 4'-OH-BDE-49, 5-OH-BDE-47 and 6-OH-BDE-47) and exposed BDE-47 were all less than $1 \%$ (Hamers et al., 2008). Therefore, $\mathrm{OH}$ - and MeO-PBDEs in mollusks were not the biotransformation products of PBDEs. Bioaccumulation from natural origin may be the predominant pathway that led to the occurrence of $\mathrm{OH}-$ and MeO-PBDEs in mollusks.

\subsection{Species differences in accumulation}

Nev, Rap and Ost are commonly found in Chinese seas. Concentrations of $\Sigma \mathrm{MeO}$-PBDEs and $\Sigma \mathrm{OH}$-PBDEs were compared between $\mathrm{Nev}$ and Ost, and Rap and Ost collected from the same locations in the same year using concentration ratios (concentration in Ost is as 1). Concentration ratios in Nev ranged from 0.01 to 0.34 (mean of 0.08 ) for $\mathrm{MeO}-\mathrm{PBDEs}$, and from 0.07 to 0.94 (mean of 0.44 ) for OH-PBDEs. Concentration ratios in Rap ranged from 0.04 to 1.46 (mean of 0.27 ) for MeO-PBDEs, and from 0.07 to 3.45 (mean of 0.87 ) for OH-PBDEs. Apparently, MeO-PBDEs and OH-PBDEs were accumulated more in Ost than in Rap and Nev. MeO-PBDEs and OH-PBDEs may have similar mechanisms of bioaccumulation in mollusks. Ost are Lamillibranchia bivalve and filter feeders feeding on plankton. Nev and Rap are carnivorous snails and feed on shellfish including Ost. The mean trophic levels of Ost, Nev and Rap are 3.0, 3.2, and 3.4, respectively, according to the previous report (Zhu et al., 2012). Trophic dilution rather than magnification were observed and were consistent with the results obtained by Zhu et al. (Zhu et al., 2012). The lipid contents of Ost, Nev and Rap are $15.7 \% \pm 2.2 \%, 6.2 \% \pm 0.1 \%$, and $6.7 \% \pm 1.8 \%$, respectively. Results showed the lipid contents had stronger relationships with $\Sigma \mathrm{OH}-$ PBDEs and $\Sigma \mathrm{MeO}-\mathrm{PBDEs}$ than trophic levels. It was assumed that Ost which have relatively higher lipid contents have greater bioaccumulative abilities of MeO-PBDEs and OH-PBDEs than Nev and Rap. The levels of $\Sigma O H-P B D E s$ were mainly higher than that of $\Sigma \mathrm{MeO}$-PBDEs in all mollusks except Ost collected from Tianjin and Penglai, suggesting the existence of selective enrichment of pollutants for mollusk species to some extent. Species differences in profiles of OH-PBDE and MeO-PBDE congeners were also studied (Fig. 3). In mollusk from both Tianjin and Penglai, the proportion of 6-OH-BDE-47 in the sum of OH- and MeO-PBDEs ranked as Os$\mathrm{t}<\mathrm{Rap}<\mathrm{Nev}$. The proportion of $2^{\prime}-\mathrm{OH}-\mathrm{BDE}-68$ was lower in Ost than in Rap and Nev, however, the proportion of 2'-MeO-BDE-68 was much higher in Ost than in Rap and Nev. 6-MeO-BDE-85 can only be found in Ost. 4-MeO-BDE-42 and 6'-MeO-BDE-99 can be detected in a portion of Rap and Ost samples, but were undetectable in all Nev samples. These profiles differences may be attributed to congener-specific dietary exposure or different biotransformation capacities between mollusk species. 


\subsection{Spatial distribution}

Three representative sampling sites were selected to assess the spatial distribution of $\mathrm{OH}-$ and $\mathrm{MeO}-\mathrm{PBDEs}$ in mollusks. The highest concentration of $\Sigma \mathrm{MeO}$-PBDEs and $\Sigma \mathrm{OH}$-PBDEs were all found in Ost sample collected in Weihai. Average $\Sigma \mathrm{MeO}-\mathrm{PBDEs}$ concentration and average $\Sigma O H-P B D E s$ concentration among four years in mollusk species from different cities were shown in Fig. 4. The average levels in mollusk mainly gradually increased in order of Tianjin < Penglai < Weihai. Statistical analysis was executed with SPSS 16.0. OH-PBDEs levels in mollusks were statistically different between Tianjin and Weihai $(p<0.01)$ using the Tukey test. There was no known anthropogenic source for $\mathrm{OH}$ - and $\mathrm{MeO}-\mathrm{PBDEs}$, so the spatial distribution of these chemicals may not be related to industrial activities and population of the three cities. Sampling sea area may be a potential affecting factor. Tianjin is located along Bohai Sea which is China's continental sea. This semi closed sea area is far away from ocean and strongly affected by surrounding continent. Therefore, the temperature and salinity of seawater were distinctly different from oceans (Chen, 2009). Weihai is located along the Yellow Sea which is marginal sea of the Pacific Ocean. This sea area has unobstructed seawater exchange with ocean. Since most detected $\mathrm{OH}$ - and MeO-PBDEs in oceans were regarded as marine natural products, diverse marine environment may lead to the different levels of $\mathrm{OH}$ - and MeO-PBDEs in organisms. Penglai is located between Bohai Sea and Yellow Sea. So, the mollusks lived in this area were affected by both seas. That is why $\Sigma \mathrm{MeO}-\mathrm{PBDEs}$ and $\Sigma \mathrm{OH}-\mathrm{PBDEs}$ in most mollusk samples collected in Penglai were higher than that of Tianjin and lower than that of Weihai.

\subsection{Temporal trends}

The temporal trends of $\Sigma \mathrm{MeO}-\mathrm{PBDEs}$ and $\Sigma \mathrm{OH}-\mathrm{PBDEs}$ in mollusks were illustrated in this work, as shown in Fig. 2. $\Sigma$ OH-PBDEs in Rap from Penglai increased from $289 \mathrm{pg} \mathrm{g}^{-1} \mathrm{dw}$ in 2007 to $853 \mathrm{pg} \mathrm{g}^{-1} \mathrm{dw}$ in 2011 (Spearman's rank correlation coefficient: $\left.r^{2}=0.97, p<0.01\right)$, and that in Ost from Weihai increased from $1110 \mathrm{pg} \mathrm{g}^{-1} \mathrm{dw}$ in 2007 to $2540 \mathrm{pg} \mathrm{g}^{-1} \mathrm{dw}$ in $2011\left(r^{2}=0.74\right.$, $p=0.09$ ). $\Sigma \mathrm{MeO}-\mathrm{PBDEs}$ in Ost in Penglai decreased from $1610 \mathrm{pg} \mathrm{g}^{-1} \mathrm{dw}$ in 2007 to $772 \mathrm{pg} \mathrm{g}^{-1} \mathrm{dw}$ in $2011\left(r^{2}=0.88\right.$, $p<0.05$ ). For other mollusk samples, no gradually declining or rising concentration between 2007 and 2011 was observed. There

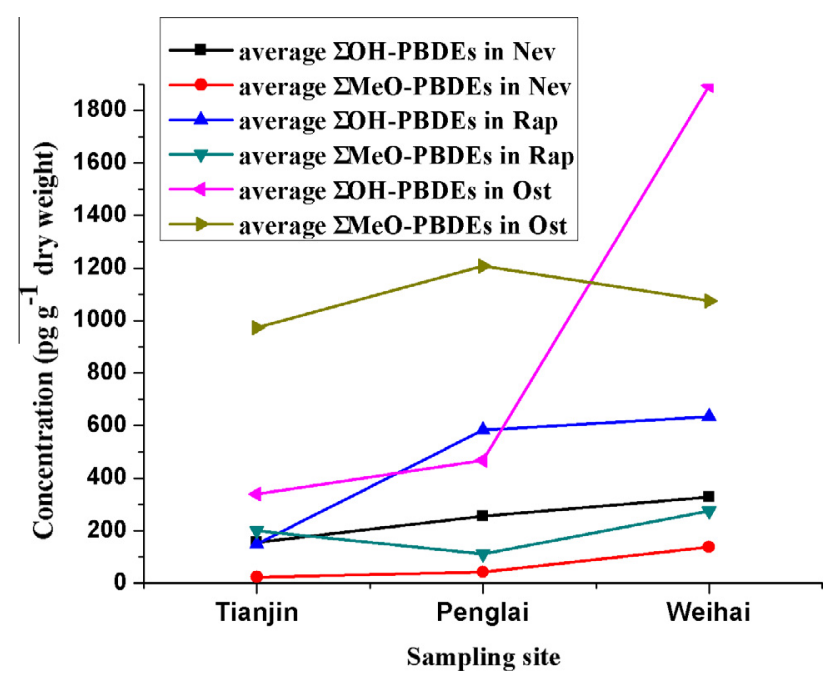

Fig. 4. Average $\Sigma \mathrm{MeO}-\mathrm{PBDEs}$ concentrations and average $\Sigma O H-P B D E s$ concentrations among four years in mollusks from different cities. was also no obvious temporal trend found for the proportion of $\mathrm{OH}-$ and $\mathrm{MeO}-\mathrm{PBDE}$ congeners in mollusks during the sampling period. To the best of our knowledge, there were no reported data about the temporal trends of $\mathrm{OH}-$ and $\mathrm{MeO}-\mathrm{PBDEs}$ concentrations in marine animals in several years. It is still difficult to clarify the reason why some mollusks showed obvious temporal variation.

\subsection{Correlations between PBDEs, MeO-PBDEs and OH-PBDEs}

The statistical relationships between PBDEs, OH-PBDEs and $\mathrm{MeO}-\mathrm{PBDEs}$ were studied to further explore the possible sources of OH-PBDEs and MeO-PBDEs in mollusks. Fig. 5 shows the correlations between target compounds in all mollusk species. In this study, $\Sigma \mathrm{OH}-\mathrm{PBDEs}$ and $\Sigma$ PBDEs $(r=0.12, p=0.50)$, and $\Sigma \mathrm{MeO}-$ PBDEs and $\Sigma$ PBDEs $(r=0.28, p=0.052)$ showed no significant correlations, suggesting that $\mathrm{OH}-$ and MeO-PBDEs did not mainly originate from PBDEs. $\Sigma$ MeO-PBDEs and $\Sigma$ OH-PBDEs $(r=0.49$, $p=0.001$ ) showed significant positive correlation. Moreover, individual isomers: 6-OH-BDE-47 and 2'-OH-BDE-68 $(r=0.84$, $p<0.001), \quad 6-\mathrm{MeO}-\mathrm{BDE}-47$ and $2^{\prime}$-MeO-BDE-68 $(r=0.72, p<$ $0.001)$, and 6-OH-BDE-47 and 6-MeO-BDE-47 $(r=0.51, p<0.001)$ showed significant positive correlation. From these results, several assumptions can be obtained as follows: (1) MeO-PBDEs and OH-PBDEs may share a common source in marine environment such as biosynthesis by red algae (Malmvarn et al., 2005); (2) $\mathrm{MeO}-\mathrm{PBDEs}$ and OH-PBDEs may have similar bioaccumulation potential in mollusks; (3) Biotransformation process may happen between MeO-PBDEs and OH-PBDEs in mollusks. MeO-PBDEs were regarded as an important contributor to the formation of OH-PBDEs (Wan et al., 2009), OH-PBDEs were also found to form MeO-PBDEs via methylation reaction (Wan et al., 2010). 2'-OHBDE-68 and 2'-MeO-BDE-68 $(r=0.19, p=0.28)$ showed no significant correlation, maybe due to their low interconversion potential in mollusks. No significant linear relationships were found between 6-OH-BDE-47 and precursor BDE-47 $(r=0.08, p=0.64)$, and $6-\mathrm{MeO}-\mathrm{BDE}-47$ and precursor BDE-47 $(r=0.13, p=0.44)$, which further supported the hypothesis that PBDE was not a primary origin for $\mathrm{OH}$ - and MeO-PBDEs in mollusks.

Naturally occurring $\mathrm{OH}$ - and $\mathrm{MeO}-\mathrm{PBDEs}$ have a similarity in structure that they all have a methoxyl or hydroxyl group in the ortho position relative to the ether bond (Maervoet et al., 2004), such as 6-MeO-BDE-47, 2'-MeO-BDE-68, 6-OH-BDE-47 and 2'-OHBDE-68 which were the dominant $\mathrm{OH}-$ and $\mathrm{MeO}-\mathrm{PBDE}$ congeners in mollusks. The current thinking is that $\mathrm{OH}$ - and MeO-PBDEs found in mollusks are mostly a consequence of accumulation via natural sources in marine environments. However, mutual transformation pathway between $\mathrm{OH}$ - and MeO-PBDEs may also play an important role in their occurrence in mollusk species. Marine products are an important part of the diet of coastal residents. Seafood consumption were considered to contribute to the load of OH-PBDEs in biosolids in wastewater treatment plants (Sun et al., 2012b). Seafood processing factory and seafood market have been found as important sources that $\mathrm{MeO}$ - and OH-PBDEs entered soil and plants (Sun et al., 2013). Consumption of marine products could represent an important source of OH-PBDEs and MeO-PBDEs exposure for humans. The results in this study are important to help to evaluate the potential exposure risks of $\mathrm{OH}-$ and $\mathrm{MeO}-\mathrm{PBDEs}$ for the environment and human health.

\section{Conclusion}

In this study, OH-PBDEs and MeO-PBDEs were measured in three mollusk species collected from three coastal cities. Eight MeO-PBDE congeners and two OH-PBDE congeners were identified. 6-MeO-BDE-47, 2'-MeO-BDE-68, 6-OH-BDE-47 and 2'-OH- 

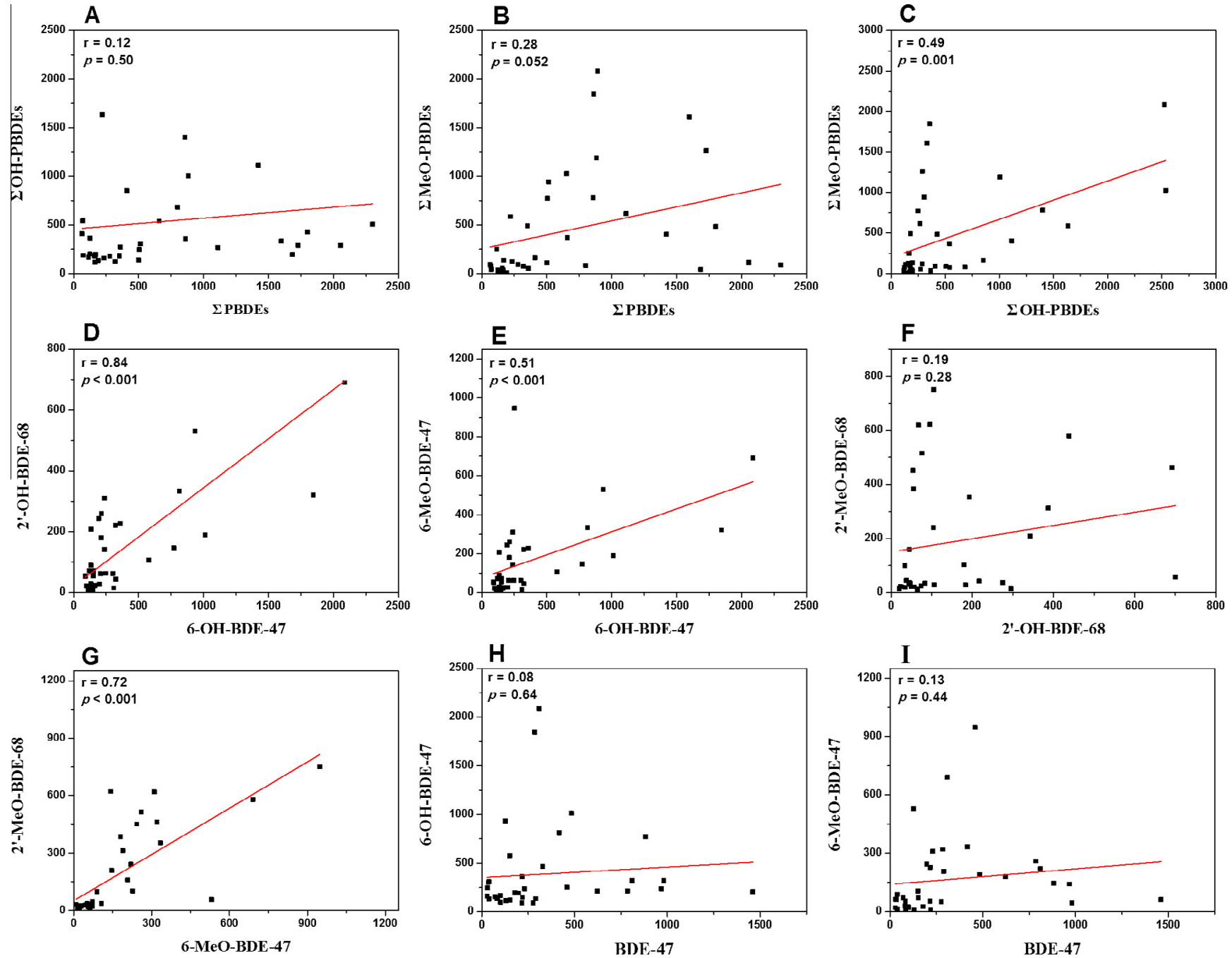

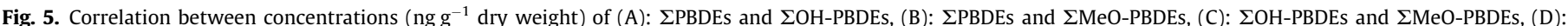

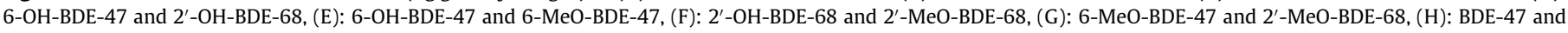
6-OH-BDE-47, (I): BDE-47 and 6-MeO-BDE-47 in 36 mollusk samples. $p$ Values: Spearman's rank correlation coefficients.

BDE-68 were the predominant contaminants. Species differences in accumulation showed the levels of $\mathrm{OH}$ - and $\mathrm{MeO}-\mathrm{PBDEs}$ were higher in Ost than in Nev and Rap. Different sampling sea area can lead to distinct spatial distribution that $\mathrm{OH}-$ and MeO-PBDEs concentrations were generally higher in Weihai than in Tianjin. Temporal trends of $\mathrm{OH}-$ and MeO-PBDEs in mollusks of Chinese coastal areas were investigated for the first time in this work. For a portion of mollusks, a declining or rising concentration trend from 2007 to 2011 was observed. Statistical relationships between PBDEs, OH-PBDEs and MeO-PBDEs showed that PBDE was not a primary source for the existence of $\mathrm{OH}$ - and $\mathrm{MeO}-\mathrm{PBDE}$ in marine environment. Significant correlations were observed between OH-PBDEs and MeO-PBDEs, suggesting they may have mutual transformation processes or share a common source or similar accumulation behavior in mollusks.

\section{Acknowledgements}

This work was jointly supported by the National Basic Research Program of China (No. 2009CB421603), the National Natural Science Foundation of China (Nos. 21177147 and 21277153), and Important Directional Item of the Chinese Academy of Sciences (No. KZCX2-EW-QN409).

\section{References}

Chen, C.T.A., 2009. Chemical and physical fronts in the Bohai, Yellow and East China seas. J. Mar. Syst. 78, 394-410.

de Wit, C.A., Alaee, M., Muir, D.C.G., 2006. Levels and trends of brominated flame retardants in the Arctic. Chemosphere 64, 209-233.

Dingemans, M.M.L., de Groot, A., van Kleef, R.G.D.M., Bergman, A., van den Berg, M., Vijverberg, H.P.M., Westerink, R.H.S., 2008. Hydroxylation increases the neurotoxic potential of BDE-47 to affect exocytosis and calcium homeostasis in PC12 cells. Environ. Health Perspect. 116, 637-643.

Hakk, H., Larsen, G., Klasson-Wehler, E., 2002. Tissue disposition, excretion and metabolism of $2,2^{\prime}, 4,4^{\prime}, 5$-pentabromodiphenyl ether (BDE-99) in the male Sprague-Dawley rat. Xenobiotica 32, 369-382.

Hamers, T., Kamstra, J.H., Sonneveld, E., Murk, A.J., Visser, T.J., Van Velzen, M.J.M. Brouwer, A., Bergman, A., 2008. Biotransformation of brominated flame retardants into potentially endocrine-disrupting metabolites, with special attention to 2,2',4,4'-tetrabromodiphenyl ether (BDE-47). Mol. Nutr. Food Res. 52, 284-298.

Hendriks, H.S., Fernandes, E.C.A., Bergman, A., van den Berg, M., Westerink, R.H.S., 2010. PCB-47, PBDE-47, and 6-OH-PBDE-47 differentially modulate human $\operatorname{GABA}(\mathrm{A})$ and alpha(4)beta(2) nicotinic acetylcholine receptors. Toxicol. Sci. 118, 635-642.

Hites, R.A., 2004. Polybrominated diphenyl ethers in the environment and in people: a meta-analysis of concentrations. Environ. Sci. Technol. 38, 945-956.

Isobe, T. Takada, $\mathrm{H}$., Kanai, M., Tsutsumi, S., Isobe, K.O., Boonyatumanond, $\mathrm{R}$. Zakaria, M.P., 2007. Distribution of polycyclic aromatic hydrocarbons (PAHs) and phenolic endocrine disrupting chemicals in south and southeast Asian mussels. Environ. Monit. Assess. 135, 423-440.

Kelly, B.C., Ikonomou, M.G., Blair, J.D., Gobas, F.A.P.C., 2008. Hydroxylated and methoxylated polybrominated diphenyl ethers in a Canadian Arctic marine food web. Environ. Sci. Technol. 42, 7069-7077. 
Li, F., Xie, Q., Li, X.H., Li, N., Chi, P., Chen, J.W., Wang, Z.J., Hao, C., 2010. Hormone activity of hydroxylated polybrominated diphenyl ethers on human thyroid receptor-beta: in vitro and in silico investigations. Environ. Health Perspect. 118, 602-606.

Maervoet, J., Covaci, A., Schepens, P., Sandau, C.D., Letcher, R.J., 2004. A reassessment of the nomenclature of polychlorinated biphenyl (PCB) metabolites. Environ. Health Perspect. 112, 291-294.

Malmvarn, A., Marsh, G., Kautsky, L., Athanasiadou, M., Bergman, A., Asplund, L., 2005. Hydroxylated and methoxylated brominated diphenyl ethers in the red algae Ceramium tenuicorne and blue mussels from the Baltic Sea. Environ. Sci. Technol. 39, 2990-2997.

Malmvarn, A., Zebuhr, Y., Kautsky, L., Bergman, A., Asplund, L., 2008. Hydroxylated and methoxylated polybrominated diphenyl ethers and polybrominated dibenzo-p-dioxins in red alga and cyanobacteria living in the Baltic Sea. Chemosphere 72, 910-916.

Meerts, I.A.T.M., Letcher, R.J., Hoving, S., Marsh, G., Bergman, A., Lemmen, J.G., van der Burg, B., Brouwer, A., 2001. In vitro estrogenicity of polybrominated diphenyl ethers, hydroxylated PBDEs, and polybrominated bisphenol A compounds. Environ. Health Perspect. 109, 399-407.

Morck, A., Hakk, H., Orn, U., Wehler, E.K., 2003. Decabromodiphenyl ether in the rat: absorption, distribution, metabolism, and excretion. Drug Metab. Dispos. 31, 900-907.

Nomiyama, K., Eguchi, A., Mizukawa, H., Ochiai, M., Murata, S., Someya, M., Isobe, T. Yamada, T.K., Tanabe, S., 2011a. Anthropogenic and naturally occurring polybrominated phenolic compounds in the blood of cetaceans stranded along Japanese coastal waters. Environ. Pollut. 159, 3364-3373.

Nomiyama, K., Uchiyama, Y., Horiuchi, S., Eguchi, A., Mizukawa, H., Hirata, S.H., Shinohara, R., Tanabe, S., 2011b. Organohalogen compounds and their metabolites in the blood of Japanese amberjack (Seriola quinqueradiata) and scalloped hammerhead shark (Sphyrna lewini) from Japanese coastal waters. Chemosphere 85, 315-321.

Orn, U., Klasson-Wehler, E., 1998. Metabolism of 2,2',4,4'-tetrabromodiphenyl ether in rat and mouse. Xenobiotica 28, 199-211.

Routti, H., Letcher, R.J., Chu, S.G., Van Bavel, B., Gabrielsen, G.W., 2009. Polybrominated diphenyl ethers and their hydroxylated analogues in ringed seals (Phoca hispida) from Svalbard and the Baltic Sea. Environ. Sci. Technol. 43, 3494-3499.

Sinkkonen, S., Rantalainen, A.L., Paasivirta, J., Lahtipera, M., 2004. Polybrominated methoxy diphenyl ethers (MeO-PBDEs) in fish and guillemot of Baltic, Atlantic and Arctic environments. Chemosphere 56, 767-775

Sun, J.T., Liu, J.Y., Liu, Q., Qu, G.B., Ruan, T., Jiang, G.B., 2012a. Sample preparation method for the speciation of polybrominated diphenyl ethers and their methoxylated and hydroxylated analogues in diverse environmental matrices. Talanta 88, 669-676.

Sun, J.T., Liu, J.Y., Liu, Q., Ruan, T., Yu, M., Wang, Y.W., Wang, T., Jiang, G.B., 2012b. Hydroxylated polybrominated diphenyl ethers (OH-PBDEs) in biosolids from municipal wastewater treatment plants in China. Chemosphere 90, 2388-2395.

Sun, J.T., Liu, J.Y., Liu, Y.W., Jiang, G.B., 2013. Levels and distribution of methoxylated and hydroxylated polybrominated diphenyl ethers in plant and soil samples surrounding a seafood processing factory and a seafood market. Environ. Pollut. $176,100-105$.

Teuten, E.L., Xu, L., Reddy, C.M., 2005. Two abundant bioaccumulated halogenated compounds are natural products. Science 307, 917-920.

Ucan-Marin, F., Arukwe, A., Mortensen, A., Gabrielsen, G.W., Fox, G.A., Letcher, R.J., 2009. Recombinant transthyretin purification and competitive binding with organohalogen compounds in two gull species (Larus argentatus and Larus hyperboreus). Toxicol. Sci. 107, 440-450.

Unson, M.D., Holland, N.D., Faulkner, D.J., 1994. A Brominated secondary metabolite synthesized by the cyanobacterial symbiont of a marine sponge and accumulation of the crystalline metabolite in the sponge tissue. Mar. Biol. 119, 1-11.

Valters, K., Li, H.X., Alaee, M., D’Sa, I., Marsh, G., Bergman, A., Letcher, R.J., 2005 Polybrominated diphenyl ethers and hydroxylated and methoxylated brominated and chlorinated analogues in the plasma of fish from the Detroit River. Environ. Sci. Technol. 39, 5612-5619.

Van Boxtel, A.L., Kamstra, J.H., Cenijn, P.H., Pieterse, B., Wagner, M.J., Antink, M., Krab, K., Van Der Burg, B., Marsh, G., Brouwer, A., Legler, J., 2008. Microarray analysis reveals a mechanism of phenolic polybrominated diphenylether toxicity in zebrafish. Environ. Sci. Technol. 42, 1773-1779.

Wan, Y., Liu, F.Y., Wiseman, S., Zhang, X.W., Chang, H., Hecker, M., Jones, P.D., Lam, M.H.W., Giesy, J.P., 2010. Interconversion of hydroxylated and methoxylated polybrominated diphenyl ethers in Japanese Medaka. Environ. Sci. Technol. 44, 8729-8735.

Wan, Y., Wiseman, S., Chang, H., Zhang, X.W., Jones, P.D., Hecker, M., Kannan, K., Tanabe, S., Hu, J.Y., Lam, M.H.W., Giesy, J.P., 2009. Origin of hydroxylated brominated diphenyl ethers: natural compounds or man-made flame retardants? Environ. Sci. Technol. 43, 7536-7542.

Wang, S., Zhang, S.Z., Huang, H.L., Lu, A.X., Ping, H., 2012. Debrominated, hydroxylated and methoxylated metabolism in maize (Zea mays L.) exposed to lesser polybrominated diphenyl ethers (PBDEs). Chemosphere 89, 1295-1301.

Wolkers, H., Van Bavel, B., Derocher, A.E., Wiig, O., Kovacs, K.M., Lydersen, C. Lindstrom, G., 2004. Congener-specific accumulation and food chain transfer of polybrominated diphenyl ethers in two Arctic food chains. Environ. Sci. Technol. 38, 1667-1674

Zhang, K., Wan, Y., An, L.H., Hu, J.Y., 2010a. Trophodynamics of polybrominated diphenyl ethers and methoxylated polybrominated diphenyl ethers in a marine food web. Environ. Toxicol. Chem. 29, 2792-2799.

Zhang, K., Wan, Y., Giesy, J.P., Lam, M.H.W., Wiseman, S., Jones, P.D., Hu, J.Y., 2010b. Tissue concentrations of polybrominated compounds in Chinese Sturgeon (Acipenser sinensis): origin, hepatic sequestration, and maternal transfer. Environ. Sci. Technol. 44, 5781-5786.

Zhang, K., Wan, Y., Jones, P.D., Wiseman, S., Giesy, J.P., Hu, J.Y., 2012. Occurrences and fates of hydroxylated polybrominated diphenyl ethers in marine sediments in relation to trophodynamics. Environ. Sci. Technol. 46, 2148-2155.

Zhu, N.L., Li, A., Wang, T., Wang, P., Qu, G.B., Ruan, T., Fu, J.J., Yuan, B., Zeng, L.X. Wang, Y.W., Jiang, G.B., 2012. Tris(2,3-dibromopropyl) isocyanurate, hexabromocyclododecanes, and polybrominated diphenyl ethers in mollusks from Chinese Bohai Sea. Environ. Sci. Technol. 46, 7174-7181. 